\title{
Depressive symptoms are associated with impaired sleep, fatigue, and disease activity in women with rheumatoid arthritis
}

Fernando Henrique Azevedo Lopes ${ }^{1}$, Max Victor Carioca Freitas², Veralice Meireles Sales de Bruin ${ }^{1}$ and Pedro Felipe Carvalhedo de Bruin ${ }^{1 *}$ (i)

\begin{abstract}
Objectives: To investigate the associations between sleep quality, fatigue, disease activity and depressive symptoms in women with rheumatoid arthritis (RA).

Methods: Female patients with previous diagnosis of RA from a Rheumatology Outpatient Clinic at a tertiary referral centre, in Fortaleza, Brazil, were consecutively recruited into the study. Sleep quality was assessed by the Pittsburgh Sleep Quality Index (PSQI); fatigue by the Fatigue Severity Scale (FSS); daytime sleepiness by the Epworth Sleepiness Scale (ESS); and depressive symptoms by the Beck Depression Inventory II (BDI-II). RA activity was measured by the disease activity score (DAS28).

Results: One hundred ten women (mean age $\pm \mathrm{SD}=51.1 \pm 13.0 \mathrm{y}$ ) were included in the study. On average, patients with depressive symptoms (BDI-II > 13), as compared to those without, showed poorer sleep quality (PSQl: $10.09 \pm$ 4.1 vs $7.33 \pm 3.55 ; p=0.001$ respectively), more fatigue (FSS: $4.69 \pm 1.89$ vs $3.34 \pm 1.8 ; p=0.001$ ) and higher disease activity level (DAS28: $4.36 \pm 1.53$ vs $3.7 \pm 1.39 ; p=0,047$ ). The logistic regression analysis showed that sleep quality is an independent predictor of depressive symptom severity.

Conclusion: Depressive symptoms, impaired sleep and fatigue are common in women with RA. Poor sleep is associated with greater frequency and severity of depressive symptoms in these patients, suggesting that screening for sleep and mood problems may be relevant both in clinical research and routine patient care. Future studies investigating the impact of measures to promote healthy sleep on depressive symptom control in this patient population are warranted.
\end{abstract}

Keywords: Rheumatoid arthritis, Sleep, Fatigue, Sleepiness, Depression

\section{Introduction}

Rheumatoid arthritis (RA) is a chronic, autoimmune disease, with overall prevalence estimated at $0.24 \%$ [1]. Women are three times more affected than men and usually report more symptoms and greater disability $[1,2]$. Although RA primarily involves the joints, it may also cause important systemic manifestations [3]. Approximately $20-30 \%$ of RA patients

\footnotetext{
* Correspondence: pedrobruin@gmail.com

'Laboratory of Sleep and Biological Rhythms, Department of Medicine, Federal University of Ceara, Rua Prof. Costa Mendes $1608-4^{\circ}$ andar, CEP 60430-971 Fortaleza, Ceara, Brazil

Full list of author information is available at the end of the article
}

become unable to work within a period of 3 years after diagnosis [4].

Depressive symptoms are common in RA [5]. Frequency of major depression in these patients has been reported to be almost 17\%, considerably higher than that of the general population [6]. In clinical practice, diagnosis of depression in patients with RA is usually complicated by the fact that somatic symptoms of depression can overlap with symptoms of RA [7]. Fatigue, a common feature of depression, can affect $41 \%$ of RA patients [8]. Depressive symptoms in RA have been associated with increased pain [9], physical disability [10] and

(c) The Author(s). 2021 Open Access This article is licensed under a Creative Commons Attribution 4.0 International License, which permits use, sharing, adaptation, distribution and reproduction in any medium or format, as long as you give appropriate credit to the original author(s) and the source, provide a link to the Creative Commons licence, and indicate if changes were made. The images or other third party material in this article are included in the article's Creative Commons licence, unless indicated otherwise in a credit line to the material. If material is not included in the article's Creative Commons licence and your intended use is not permitted by statutory regulation or exceeds the permitted use, you will need to obtain permission directly from the copyright holder. To view a copy of this licence, visit http://creativecommons.org/licenses/by/4.0/. 
comorbidities [11], reduced quality of life [12] and higher mortality levels [13]. Recently, it has been reported that baseline and persistent depressive symptoms are associated with worse response to treatment and poorer long-term health outcomes [14]. The mechanism for the relationship between mood problems and RA outcomes remains incompletely understood [15]. The association between quality of sleep and depressive symptoms has not been adequately investigated in patients with RA in Brazil.

More than half of RA patients report sleep problems, including difficulty falling asleep, nocturnal awakenings, nonrestorative sleep and fatigue, a frequency that is three times higher than that of the general population [16]. It has been previously suggested that impaired sleep in RA is mainly secondary to joint pain, disease activity and altered mood [17-19]. On the other hand, there is evidence that disturbed sleep can be involved in the genesis of inflammatory disorders [20] and poor sleep quality has been shown to exacerbate pain perception in RA patients [21]. Additionally, sleep problems are recognized as an important risk factor for depression. Individuals suffering from insomnia are twice as likely to develop depression compared to those who do not have difficulty in sleep [22].

Fatigue is major symptom in patients with RA and has been associated with sleep problems, pain and depression. There is evidence that fatigue, poor sleep quality, pain, depression may be associated with greater disability in these patients [23].

The main purpose of this study was to assess the presence of depressive symptoms and its associations with sleep quality, fatigue, and disease activity in patients with RA.

\section{Methods}

This was a cross-sectional study of women with established RA, regularly attending an outpatient clinic at Dr. César Cals General Hospital, a tertiary referral centre in Fortaleza, Brazil, between April 2014 and December 2015. Female patients older than 18 years, who met the internationally-set RA diagnosis criteria [24], and whose therapeutic regimen had not been changed in the previous 3 months, were asked to take part in the study.

Disease activity was measured using the Disease Activity Score in 28 joints (DAS28), which comprises four scoring components, namely: number of swollen joints (0 to 28); number of painful joints (0 to 28); erythrocyte sedimentation rate (ESR); and general health visual analogue scale (VAS). DAS28 final score ranges from 0 to 10 and scores $\leq 2.6$ were interpreted as remission; between 2.6 and 3.2, as low disease activity; between 3.2 and 5.1, as moderate activity; and $>5.1$ as high activity [24].

Additionally, patients answered the following questionnaires, which have been previously translated and validated for use in Brazil: Beck Depression Inventory (BDI-II) [25]; Pittsburgh Sleep Quality Index (PSQI) [26]; Epworth Sleepiness Scale (ESS) [27]; Fatigue severity Scale (FSS) [28].

Depressive symptoms were assessed by the Beck Depression Inventory (BDI-II). This instrument consists of 21 sets of statements about the occurrence of depressive symptoms in the 15 days preceding the test application. Statements are classified in a Likert scale ranging from 0 to 3 , to produce scores ranging from 0 to 63 . Patients with BDI-II score $>13$ were classified as positive for depressive symptoms $[25,29]$.

Sleep quality was assessed by the PSQI, a self-report questionnaire that consists of 19 items, creating seven components, each one dealing with a major aspect of sleep: subjective sleep quality, sleep latency, sleep duration, habitual sleep efficiency, sleep disturbances, use of sleeping medication and daytime dysfunctions. These components are weighted equally on a $0-3$ scale, providing a global score ranging from 0 to 21 [26]. In the present study, scores higher than 5 were considered indicative of poor sleep quality. This cut-off point has shown satisfactory sensitivity $(89.6 \%)$ and specificity $(86.5 \%)$ to differentiate good from poor sleep quality [30].

Daytime sleepiness was evaluated by the Epworth Sleepiness Scale (ESS), a widely used instrument that infers the patient's likelihood of sleeping or dozing in eight daily life situations. This likelihood may range from zero (none) to three (high) for each situation. The final score corresponds to the sum of the values attributed to each individual question. Values higher than or equal to 10 were considered indicative of excessive daytime sleepiness [31].

Fatigue level was measured by the Fatigue Severity Scale (FSS), which consists of a sequence of 9 statements about the possible impact of fatigue on the responder's daily activities. For each statement, the subjects are asked to attribute a value from 1 to 7 , depending on how appropriate they felt the statement applied to them over the previous 7 days. A low value indicates that the statement is not very appropriate whereas a high value indicates agreement. The final score represents the mean value calculated for the 9 items. Values higher than 4 indicate significant fatigue levels [32].

Additional socio-demographic and clinical data, including age, gender, time from diagnosis, and therapeutic regimen were gathered through interview and chart review. 


\section{Statistical analysis}

Data are presented as mean \pm standard deviation (SD) or frequency, as appropriate. Normality of the numerical data was assessed by the Kolmogorov-Smirnov test. Unpaired Student's t-test was used for variables with normal distribution. The Mann-Whitney test was used for non-normal variables. Categorical variables were analysed by the Fisher exact test. For comparative analysis, participants were allocated into two categories, according to the presence (BDI-II >13) or absence of depressive symptoms. Spearman's correlation coefficients were calculated to examine possible correlations between BDI-II and other variables. Logistic regression analysis was performed to identify independent predictors for the occurrence of depressive symptoms using a forward stepwise approach. The Statistical Package for Social Science (SPSS) v22.0 (IBM CO., Armonk, NY, USA) was used for data analysis. A $p$-value $<0.05$ was considered significant.

\section{Results}

One hundred and ten female patients, aged from 19 to 79 years, were included in the study. Depressive symptoms were present in $31.8 \%$ of the participants and were classified as mild $(13<\mathrm{BDI}-\mathrm{II} \leq 19)$ in 14 , moderate $(19<\mathrm{BDI}-\mathrm{II} \leq 28)$ in 13 and severe $(28<\mathrm{BDI}-\mathrm{II} \leq 63)$ in 6. Ten patients $(9.1 \%)$ were on antidepressants (Amitriptyline: $n=05$; Fluoxetine $n=02$; Duloxetine: $n=1$; Nortriptyline: $n=1$; Amitriptyline + Fluoxetine: $n=1$ ] . Poor quality sleep (PSQI $>5$ ) was observed in $70.9 \%$ of the patients; fatigue (FSS > 4) in 41.8\%; and excessive daytime sleepiness $(E S S \geq 10)$ in $39 \%$. Disease activity level was calculated in $84(76.4 \%)$ patients, for whom the erythrocyte sedimentation rate was available at the time they were included in the study and was classified as moderate / high (DAS28 > 3.2) in 59.5\%. There was no significant difference in age, time from diagnosis and questionnaire results between the 26 patients with missing DAS28 results and other study participants.

On average, patients with depressive symptoms (BDIII $>13$ ), as compared to those without, showed poorer sleep quality (PSQI: $10.09 \pm 4.1$ vs $7.33 \pm 3.55 ; p=0.001$ ), more fatigue (FSS: $4.69 \pm 1.89$ vs $3.34 \pm 1.8 ; p=0.001$ ) and higher disease activity level (DAS28: $4.36 \pm 1.53$ vs $3.7 \pm 1.39 ; p=0.047$ ). Daytime sleepiness was not significantly different between the two groups (Table 1). Analysis of the seven PSQI components showed that patients with depressive symptoms had poorer subjective sleep quality and more sleep disturbances and use of sleep medication (Fig. 1). Patients with moderate/ high disease activity (DAS28 $>3.2$ ) showed poorer sleep quality (PSQI global score: $9.91 \pm 4.08$ vs $7.0 \pm 3.67 ; p<0.01$ ) than those in remission/ low disease activity.

Sixty-nine $(62.7 \%)$ patients were on regular use of glucocorticoids, $90(81.8 \%)$ on traditional disease-modifying antirheumatic drugs; and 23 (20.9\%) on biologic diseasemodifying antirheumatic drugs.

The occurrence of depressive symptoms (BDI-II > 13) was positively correlated with sleep impairment $(r=0.378 ; p<0.001)$, fatigue $(r=0.307 ; p=0.001)$ and disease activity $(r=0.333 ; p=0.002)$. Stepwise multiple regression analysis, with age, disease duration, PSQI, DAS28, FSS, and ESS scores as independent variables, showed that the PSQI global score was an independent predictor for the occurrence of depressive symptoms (Table 2).

Table 1 Demographic and clinical characteristics, quality of sleep, fatigue, and daytime sleepiness in 110 RA female patients

\begin{tabular}{|c|c|c|c|c|}
\hline & $\begin{array}{l}\text { Total } \\
n=110\end{array}$ & $\begin{array}{l}\text { BDI-II } \leq 13 \\
n=74\end{array}$ & $\begin{array}{l}\text { BDI-II > } 13 \\
n=36\end{array}$ & $p$ \\
\hline Age, years (mean $\pm S D)$ & $51.2 \pm 8.1$ & $52.3 \pm 13.3$ & $48.6 \pm 12.15$ & $0.054^{\mathrm{b}}$ \\
\hline Disease duration, years (mean $\pm \mathrm{SD}$ ) & $8.1 \pm 7.8$ & $8.9 \pm 8.5$ & $6.4 \pm 5.7$ & $0.147^{b}$ \\
\hline DAS28 score ${ }^{a}($ mean $\pm S D)$ & $3.89 \pm 1.45$ & $3.7 \pm 1.4$ & $4.36 \pm 1.53$ & $0.047^{b}$ \\
\hline Moderate / high activity disease (DAS28 > 3,2), n (\%) & $50(59.5)$ & $31(53.4)$ & 19(73.1) & $0.100^{c}$ \\
\hline PSQl global score $($ mean \pm SD) & $8.21 \pm 3.93$ & $7.33 \pm 3.55$ & $10.09 \pm 4.1$ & $0.001^{b}$ \\
\hline Poor sleep, n (\%) & 78(70.9) & $48(64)$ & $30(85.7)$ & $0.024^{c}$ \\
\hline FSS (mean \pm SD) & $3.77 \pm 1.93$ & $3.34 \pm 1.8$ & $4.69 \pm 1.89$ & $0.001^{\mathrm{b}}$ \\
\hline Fatigue, n (\%) & $47(42.7)$ & 26(34.7) & $21(60)$ & $0.014^{c}$ \\
\hline ESS $($ mean \pm SD) & $8.73 \pm 5.41$ & $8.39 \pm 5.04$ & $9.46 \pm 6.15$ & 0.450 \\
\hline EDS, n (\%) & $43(39.1)$ & 28(37.3) & $15(42.9)$ & $0.676^{c}$ \\
\hline BDI-II (mean \pm SD) & $10.84 \pm 9.11$ & $5.55 \pm 3.94$ & $21.89 \pm 6.65$ & $<0.01^{\mathrm{b}}$ \\
\hline
\end{tabular}

$p$ values are for comparisons between groups of patients with (BDI-II > 13) and without depressive symptoms

Definition of abbreviations - BDI-II Beck Depression Inventory II, DAS28 disease activity score in 28 joints, PSQI Pittsburgh Sleep Quality Index, FSS Fatigue Severity Scale, ESS Epworth Sleepiness Scale, EDS Excessive daytime sleepiness

${ }^{a}$ DAS28 values for 84 patients

bMann-Whitney

${ }^{\mathrm{c}}$ Fisher exact test 


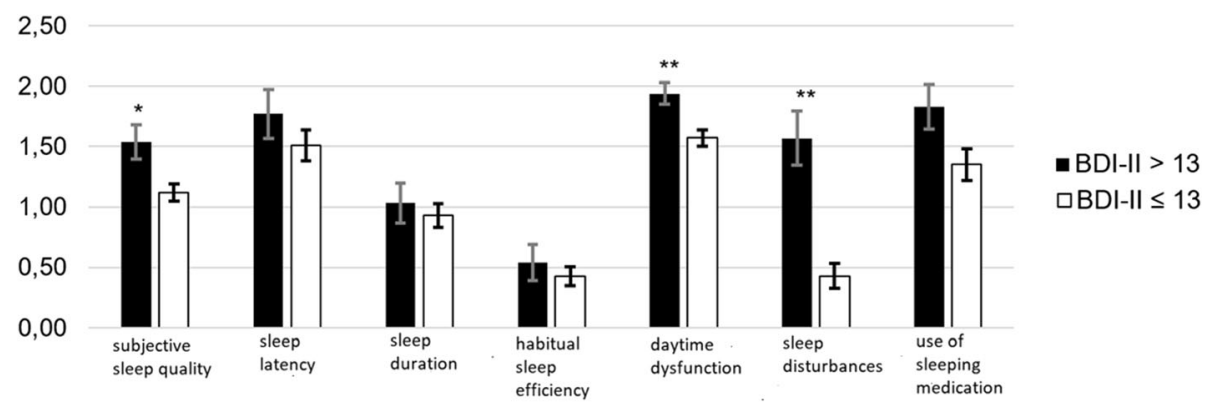

Fig. 1 Pittsburgh Sleep Quality Index components subjective sleep quality, sleep disturbances, use of sleep medication and daytime dysfunction were significantly impaired in RA patients with depressive symptoms as compared to those without depressive symptoms. Definition of abbreviations - BDI-II: Beck Depression Inventory. * $p<0,05$; ** $p<0,01$

\section{Discussion}

This study shows that depressive symptoms, sleep impairment and fatigue are very common in Brazilian women with RA. Importantly, poor sleep quality was found to be an independent predictor of depressive symptoms in these patients.

Almost one third of the study participants had depressive symptoms. Retrospective studies comprising large numbers of subjects also found a high prevalence of depressive symptoms in RA [5, 33]. A strong relationship between RA diagnosis and risk of depression was reported in 3698 newly diagnosed patients with RA. The incidence of depression in the RA cohort was 1.74-fold higher than in non-RA subjects [34]. In a retrospective study of a matched cohort of 18,285 participants it was found that RA patients were two times more likely to develop depression [35].

The present results show that the presence of depressive symptoms in patients with RA is associated with higher levels of disease activity, as previously reported [36]. In a study of 87 older women with RA, initially evaluated for depression and weekly assessed for 12 to 20 weeks for pain, depressive symptoms were found to

Table 2 Results of the stepwise multiple regression analyses using depressive symptoms as the dependent variable

\begin{tabular}{llllllll}
\hline $\begin{array}{l}\text { Independent } \\
\text { variables }\end{array}$ & $\mathbf{B}$ & SE & Wald & $\mathbf{p}$ & OR & \multicolumn{2}{c}{\begin{tabular}{l}
$\mathbf{9 5 \%}$ Cl for OR \\
\cline { 5 - 8 }
\end{tabular}} \\
\hline Age & -0.007 & 0.023 & 0.102 & 0.749 & 0.993 & 0.949 & 1.039 \\
Disease duration & -0.019 & 0.046 & 0.160 & 0.690 & 0.982 & 0.896 & 1.075 \\
DAS28 & 0.271 & 0.201 & 1.819 & 0.177 & 1.312 & 0.884 & 1.945 \\
PSQI & 0.199 & 0.082 & 5.837 & 0.016 & 1.22 & 1.038 & 1.434 \\
FSS & 0.024 & 0.019 & 1.685 & 0.194 & 1.025 & 0.988 & 1.063 \\
ESS & -0.013 & 0.049 & 0.072 & 0.789 & 0.987 & 0.897 & 1.086 \\
Constant & -4.320 & 1.724 & 6.277 & 0.012 & 0.013 & & \\
\hline
\end{tabular}

Definition of Abbreviations: BDI-II Beck Depression Inventory, DAS28 Disease activity score in 28 joint, PSQI Pittsburgh Sleep Quality Index, FSS Fatigue Severity Scale, $B$ coefficients, OR Odds ratio, $C I$ Confidence interval be related to elevations in pain [37]. The effects of depression on markers of immune activation were evaluated in another study of 45 women with RA and 106 controls with no autoimmune disease. A greater CD4 activation was found among RA patients who were depressed as compared to other groups. Depressed RA patients under stress showed the highest levels of IL-6. Those results suggest that depression plays a significant role in autoimmune processes associated with RA [38]. It has also been previously reported that baseline depression in patients with RA can predict disease activity and disability after a two-year follow-up period [14].

In this study, poor-quality sleep was found in more than two thirds of the participants and was related to disease activity. This finding is in agreement with previous reports of a high prevalence of disturbed sleep in RA, particularly, in the more active cases $[17-19,38$, 39]. Cytokines, including TNF- $\alpha$ and IL-6, which also play a significant pathogenetic role in RA, could be involved in the genesis of the sleep problems observed in these patients [40]. It has been previously reported that sleep deprivation can increase the concentration of Tolllike receptor 4 (TLR-4) which, in turn, stimulates the production of interleukin-6 (IL-6) and tumour necrosis factor - alpha (TNF- $\alpha$ ), two proinflammatory cytokines directly involved in RA [41]. Additionally, sleep deprivation can lead to greater expression of genes related to these cytokines through nuclear factor - kappa B (NF- $\mathrm{kB}$ ) activation, which is the main gene-transcription regulatory pathway in the inflammatory signalling cascade [20].

This study confirms previous reports of a high frequency of fatigue in RA [8]. Although it is generally recognized that inflammation plays a significant role in the development of fatigue in RA, there is also evidence that non-inflammatory pathways could be involved [42]. It is likely that fatigue in patients with RA has a multifactorial origin, probably involving a wide range of factors, which may include obesity, sedentary lifestyle, sleep disturbances, loss of muscle mass and depression [43]. 
More than a third of the subjects in this study reported excessive daytime sleepiness, a frequency much higher than that found in the general adult population $[44,45]$. No difference in daytime somnolence was observed between participants with and without depressive symptoms. A previous study in RA patients described a negative correlation between disease activity and subjective daytime sleepiness. Further studies are needed to clarify the relation between somnolence, disease activity, and depressive symptoms in RA [19].

The present results confirm that RA patients with depressive symptoms, on average, show higher disease activity than patients without these symptoms. Previously, an association between baseline depression symptom status and disease activity was found in a prospective study of 18,421 RA patients receiving biologic treatment. Depressive symptoms contributed to increased DAS28 over a 12-month follow-up period, and had an impact in changes in DAS28 in response to treatment. Interestingly, depression was associated with both subjective and objective aspects of disease activity, as assessed by specific components of the DAS28. It was suggested that these findings could be secondary to the negative impact of depression on health-related behaviours, particularly, medication adherence. They could also be related to biological factors, such as, systemic inflammation and elevated cytokines typically associated with disease severity in RA, which are also present in people with depressive disorder, or both [46].

An important finding of the present study is an independent association between poor-quality sleep and depressive symptoms. Disrupted sleep is generally recognized as a major feature of depression [47]. However, the relationship between poor sleep and depressive symptoms is probably bidirectional and may involve several factors [48]. Previous studies have shown a significant correlation between subjective sleep quality, as assessed by the global PSQI score, and measures of depression [49]. Additionally, depressed subjects present significantly higher PSQI scores than normal controls [30]. It has been suggested that the PSQI is better than objective measures of sleep for the detection of negative perceptions of sleep commonly found in patients with depression [50].

This study has limitations that must be considered. No male patients were included, so these results cannot be extrapolated to the entire RA population, mostly because of previously described effects of gender on disease activity measures as well as possible differences in cut-off values for some of the questionnaires that were used. Moreover, the presence of depressive symptoms assessed by the BDI-II is not sufficient for the diagnosis of depressive disorder, which requires a clinical structured interview. Besides, due to the cross-sectional design, causality cannot be implied, and prospective studies should be conducted to further investigate the associations between sleep quality, disease activity, fatigue, daytime sleepiness and depressive symptoms in RA patients.

\section{Conclusions}

This study shows a high frequency of impaired sleep, fatigue, and depressive symptoms in RA patients. Poorquality sleep, found in the majority of cases, is associated with a higher frequency and severity of depressive symptoms. These findings highlight the importance of screening for sleep and mood disorders in RA patients both in clinical trials and in clinical practice. Future studies examining the impact of measures to promote healthy sleep on depressive symptom control in this patient population are warranted.

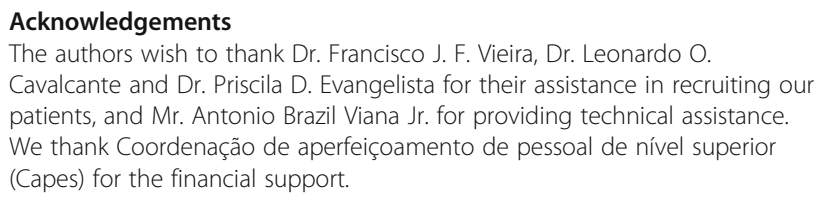

Authors' contributions

FHAL: acquisition of subjects and data, interpretation of data, preparation of manuscript. MVCF: Screening and clinical evaluation of the subjects. VMSB: critical review of manuscript. PFCB: study concept and design, analysis and interpretation of data, preparation of manuscript. The author(s) read and approved the final manuscript.

\section{Authors' information}

Not applicable.

\section{Funding \\ The funding agencies had no direct role in the conduct of the study; the collection, management, analyses, or interpretation of the data; or preparation or approval of the manuscript.}

Availability of data and materials

The datasets used and/or analysed during the current study are available from the corresponding author on reasonable request.

\section{Declarations}

\section{Ethics approval and consent to participate}

The study protocol complied with the Declaration of Helsinki. All participants signed an Informed Consent Form, which was previously approved by the local Research Ethics Committee (no. 562.792, 2014).

Consent for publication

Not applicable.

\section{Competing interests}

The authors declare that they have no competing interests.

\section{Author details}

'Laboratory of Sleep and Biological Rhythms, Department of Medicine, Federal University of Ceara, Rua Prof. Costa Mendes $1608-4^{\circ}$ andar, CEP 60430-971 Fortaleza, Ceara, Brazil. ${ }^{2}$ Dr. Cesar Cals General Hospital, Fortaleza, Ceara, Brazil. 
Received: 12 October 2020 Accepted: 2 March 2021

Published online: 16 March 2021

\section{References}

1. Hoy D, March L, Brooks P, Blyth F, Woolf A, Bain C, et al. The global burden of rheumatoid arthritis: estimates from the global burden of disease 2010 study. Ann Rheum Dis. 2014:73(6):968-74.

2. Sokka T, Toloza S, Cutolo M, Kautiainen H, Makinen H, Gogus F, et al. Women, men, and rheumatoid arthritis : analyses of disease activity , disease characteristics, and treatments in the QUEST-RA Study. Arthritis Res Ther. 2009:11(1):1-12.

3. Smolen JS, Aletaha D, McInnes IB. Rheumatoid arthritis. Lancet. 2016; 388(10055):2023-38

4. Sokka T. Work disability in early rheumatoid arthritis. Ann Rheum Dis. 2003; 21(31):S71-4.

5. Matcham F, Rayner L, Steer S, Hotopf M. The prevalence of depression in rheumatoid arthritis: a systematic review and meta-analysis. Rheumatology (Oxford). 2013;52(12):2136-48

6. Ferrari AJ, Somerville AJ, Baxter AJ, Norman R, Patten SB, Vos T, et al. Global variation in the prevalence and incidence of major depressive disorder: a systematic review of the epidemiological literature. Psychol Med. 2013;43(3): 471-81

7. Zyrianova Y, Kelly BD, Gallagher C, McCarthy C, Molloy MG, Sheehan J, et al. Depression and anxiety in rheumatoid arthritis: the role of perceived social support. Ir J Med Sci. 2006;175(2):32-6.

8. Overman $\mathrm{CL}$, Kool MB, Da Silva JAP, Geenen R. The prevalence of severe fatigue in rheumatic diseases: an international study. Clin Rheumatol. 2016; 35(2):409-15.

9. Brandstetter S, Riedelbeck G, Steinmann M, Ehrenstein B, Loss J, Apfelbacher C. Pain, social support and depressive symptoms in patients with rheumatoid arthritis: testing the stress-buffering hypothesis. Rheumatol Int. 2017;37(6):931-6

10. El-Miedany $\mathrm{YM}$, El Rasheed $\mathrm{AH}$. Is anxiety a more common disorder than depression in rheumatoid arthritis? Jt Bone Spine. 2002;69(3):300-6.

11. Katz P, Yelin E. Prevalence and correlates of depressive symptoms among persons with rheumatoid arthritis. J Rheumatol. 1993;20(5):790-6.

12. Mikuls T, Saag K, Criswell L, Merlino L, Cerhan JR. Health related quality of life in women with elderly onset rheumatoid arthritis. J Rheumatol. 2003; 30(5):952-7.

13. Ang D, Choi H, Kroenke K, Wolfe F. Comorbid depression is an independent risk factor for mortality in patients with rheumatoid arthritis. J Rheumatol. 2005;32(6):1013-9.

14. Matcham F, Norton S, Scott DL, Steer S, Hotopf M. Symptoms of depression and anxiety predict treatment response and long-term physical health outcomes in rheumatoid arthritis: secondary analysis of a randomized controlled trial. Rheumatology. 2016;55(2):268-78.

15. Sheehy C, Murphy E, Barry M. Depression in rheumatoid arthritis: underscoring the problem. Rheumatol. 2006:45(11):1325-7.

16. Sariyildiz M, Batmaz I, Bozkurt M. Sleep quality in rheumatoid arthritis: relationship between the disease severity, depression, functional status and the quality of life. J Clin Med. 2014;6(1):44-52.

17. Westhovens R, Van Der Elst K, Matthys A, Tran M, Gilloteau I. Sleep problems in patients with rheumatoid arthritis. J Rheumatol. 2014;41(1):31-40.

18. Nicassio PM, Ormseth SR, Custodio MK, Olmstead R, Weisman MH, Irwin MR Confirmatory factor analysis of the Pittsburgh sleep quality index in rheumatoid arthritis patients. Behav Sleep Med. 2014;12(1):1-12.

19. Grabovac I, Haider S, Berner C, Lamprecht T, Fenzl K, Erlacher L, et al. Sleep quality in patients with Rheumatoid Arthritis and associations with pain, disability, disease duration, and activity. J Clin Med. 2018;7(10):336.

20. Irwin MR, Wang M, Ribeiro D, Cho HJ, Ph D, Breen EC, et al. Sleep loss activates cellular inflammatory signaling. Biol Psychiatry. 2008;64(6):538-40.

21. Irwin MR, Olmstead R, Carrillo C, Sadeghi N, Fitzgerald JD, Ranganath VK, et al. Sleep loss exacerbates fatigue, depression, and pain in rheumatoid arthritis. Sleep. 2012;35(4):537-43

22. Baglioni C, Battagliese G, Feige B, Spiegelhalder K, Nissen C, Voderholzer U, et al. Insomnia as a predictor of depression: a meta-analytic evaluation of longitudinal epidemiological studies. J Affect Disord. 2011;135(1-3):10-9.

23. Luyster FS, Chasens ER, Wasko MCM, Dumbar-Jacob J. Sleep Quality and Functional Disability in Patients with Rheumatoid Arthritis. J Clin Sleep Med. 2011;7(1):49-55.
24. Aletaha D, Neogi T, Silman AJ, Funovits J, Felson DT, Bingham CO, et al. 2010 rheumatoid arthritis classification criteria: an American College of Rheumatology/European league against rheumatism collaborative initiative. Arthritis Rheum. 2010;62(9):2569-81.

25. Gomes-Oliveira MH, Gorenstein C, Neto FL, Andrade LH, Wang YP. Validation of the Brazilian Portuguese version of the Beck depression inventory-II in a community sample. Rev Bras Psiquiatr. 2012;34(4):389-94.

26. Bertolazi AN, Fagondes SC, Hoff LS, Dartora EG, da Silva Miozzo IC, de Barba MEF, et al. Validation of the Brazilian Portuguese version of the Pittsburgh sleep quality index. Sleep Med. 2011;12(1):70-5.

27. Naimaier Bertolazi A, Chaves Fagondes S, Santos Hoff L, Dallagasperina Pedro V, Saldanha Menna Barreto S, Johns MW, et al. Portuguese-language version of the Epworth sleepiness scale: validation for use in Brazi** *** Validação da escala de sonolência de Epworth em português para uso no Brasil. J Bras Pneumol. 2009:35(9):877-83.

28. Mendes MF, Pavan K, Marangoni BEM, Schmidt KB. Adaptação transcultural da escala de gravidade de fadiga para a língua portuguesa. Med Reabil. 2008;27(3):69-71.

29. Beck AT, Steer RA, Ball R, Ranieri W. Comparison of Beck Depression Inventories -IA and -II in psychiatric outpatients. J Pers Assess. 1996;67:58897.

30. Buysse DJ, Reynolds CF, Monk TH, Berman SR, Kupfer DJ, III CFR, et al. The Pittsburgh sleep quality index: a new instrument for psychiatric practice and research. Psychiatry Res. 1989;28(2):193-213.

31. Johns MW. A new method for measuring daytime sleepiness: the Epworth sleepiness scale. Sleep. 1991;14(6):540-5.

32. Krupp LB, La Rocca NG, Muir-Nash J, Steinberg AD. The fatigue severity scale. Application to patients with multiple sclerosis and systemic lupus erythematosus. Arch Neurol. 1989;46(10):1121-3.

33. Isik A, Koca SS, Ozturk A, Mermi O. Anxiety and depression in patients with rheumatoid arthritis. Clin Rheumatol. 2007;26(6):872-8.

34. Lin M-C, Guo H-R, Lu M-C, Livneh H, Lai N-S, Tsai T-Y. Increased risk of depression in patients with rheumatoid arthritis: a seven-year populationbased cohort study. Clinics (Sao Paulo). 2015;70(2):91-6.

35. Wang S-L, Chang C-H, Hu L-Y, Tsai S-J, Yang AC, You Z-H. Risk of developing depressive disorders following rheumatoid arthritis: a nationwide population-based study. PLoS One. 2014;9(9):e107791.

36. Rathbun AM, Reed GW, Harrold LR. The temporal relationship between depression and rheumatoid arthritis disease activity, treatment persistence and response: a systematic review. Rheumatology. 2013;52:1785-94.

37. Zautra A, Smith B. Depression and reactivity to stress in older women with rheumatoid arthritis and osteoarthritis. Psychosom Med. 2001;63(4):687-96.

38. Zautra A, Yocum D, Villanueva I, Smith B, Davis M, Attrep J, et al. Immune activation and depression in women with rheumatoid arthritis. J Rheumatol. 2004;31(3):457-63.

39. Austad C, Kvien TK, Olsen IC, Uhlig T. Sleep disturbance in patients with rheumatoid arthritis is related to fatigue, disease activity, and other patientreported outcomes. Scand J Rheumatol. 2016:9742(June):1-9.

40. Taylor-Gjevre RM, Gjevre JA, Nair BV, Skomro RP, Lim HJ. Improved sleep efficiency after anti-tumor necrosis factor a therapy in rheumatoid arthritis patients. Ther Adv Musculoskelet Dis. 2011;3(5):227-33.

41. Irwin MR, Wang M, Campomayor CO, Collado-Hidalgo A, Cole S. Sleep deprivation and activation of morning levels of cellular and genomic markers of inflammation. Arch Intern Med. 2006;166(16):1756-62.

42. van Steenbergen HW, Tsonaka R, Huizinga TWJ, Boonen A, Mil AHM van der $H$. Fatigue in rheumatoid arthritis; a persistent problem: a large longitudinal study. RMD Open. 2015;1(1):e000041.

43. Katz P, Margaretten M, Trupin L, Schmajuk G, Yazdany J, Yelin E. Role of sleep disturbance, depression, obesity, and physical inactivity in fatigue in rheumatoid arthritis. Arthritis Care Res (Hoboken). 2016;68(1):81-90.

44. Ford ES, Cunningham TJ, Giles WH, Croft JB. Trends in insomnia and excessive daytime sleepiness among US adults from 2002 to 2012. Sleep Med. 2016:16(3):372-8

45. Santos-Silva R, Bittencourt LRA, Pires MLN, de Mello MT, Taddei JA, Benedito-Silva AA, et al. Increasing trends of sleep complaints in the city of Sao Paulo, Brazil. Sleep Med. 2010;11(6):520-4.

46. Matcham F, Davies R, Hotof M, Hyrich K, Norton S, Steer S, et al. The relationship between depression and biologic treatment responsein rheumatoid arthritis: an analysis of the British Society for Rheumatology biologics register. Rheumatology. 2018;57(5):835-43.

47. Baglioni C, Spiegelhalder K, Lombardo C, Riemann D. Sleep and emotions: a focus on insomnia. Sleep Med Rev. 2010;14(4):227-38. 
48. Barclay NL, Gregory AM. Quantitative genetic research on sleep: a review of normal sleep, sleep disturbances and associated emotional, behavioural, and health-related difficulties. Sleep Med Rev. 2013;17(1):29-40.

49. Carpenter JS, Andrykowski MA. Psychometric evaluation of the Pittsburgh sleep quality index. J Psychosom Res. 1998;45(1):5-13.

50. Grandner MA, Kripke DF, Yoon I, Youngstedt SD. Criterion validity of the Pittsburgh sleep quality index : investigation in a non-clinical sample. Sleep Biol Rhythms. 2006;4(June):129-36.

\section{Publisher's Note}

Springer Nature remains neutral with regard to jurisdictional claims in published maps and institutional affiliations.

Ready to submit your research? Choose BMC and benefit from:

- fast, convenient online submission

- thorough peer review by experienced researchers in your field

- rapid publication on acceptance

- support for research data, including large and complex data types

- gold Open Access which fosters wider collaboration and increased citations

- maximum visibility for your research: over $100 \mathrm{M}$ website views per year

At BMC, research is always in progress.

Learn more biomedcentral.com/submissions 